\title{
ASSOCIATION BETWEEN ALCOHOL CONSUMPTION AND ACADEMIC ACHIEVEMENT: A CROSS-SECTIONAL STUDY
}

\author{
Dong Jun Sung ${ }^{1}$, Wi-Young So ${ }^{2}$, Taikyeong Ted. Jeong ${ }^{3}$ \\ ${ }^{1}$ Division of Sport Science, College of Science and Technology, Konkuk University, Chungju, Republic of Korea \\ ${ }^{2}$ College of Humanities and Arts, Sports and Health Care, Korea National University of Transportation, Chungju, Republic of Korea \\ ${ }^{3}$ Department of Computer Science and Engineering, Seoul Women's University, Seoul, Republic of Korea
}

\begin{abstract}
SUMMARY
Aim: Alcohol consumption among adolescents is a serious public health problem in South Korea. Our study examined the relationship between alcohol consumption and academic achievement in Korean adolescents. In 2011, 75,643 students from seventh to twelfth grade participated in the Seventh Korea Youth Risk Behaviour Web-based Survey (KYRBWS-VII)

Method: We performed multivariate logistic regression analysis to examine the associations between alcohol consumption, frequency of severe alcohol intoxication, and academic achievement for both girls and boys.

Results: Compared to non-drinkers, the odds of achieving average or higher academic performance significantly decreased for both boys and girls with increasing number of days per month with reported alcohol consumption $(p \leq 0.008)$. Further, odds of achieving average or higher academic performance significantly decreased with increasing amounts of alcohol consumed compared to non-drinkers $(p \leq 0.026)$. Additionally, the odds of achieving average or higher academic performance according to the frequency of severe alcohol intoxication were only significantly decreased for $1-2$ days per month of severe intoxication $(p<0.001)$.

Conclusion: Both boys and girls with increased alcohol consumption and frequency of severe alcohol intoxication had below average academic achievement in Korea. To improve academic achievement, we recommend interventions that reduce alcohol consumption among adolescents.
\end{abstract}

Key words: academic achievement, adolescent, alcohol, Korea Youth Risk Behaviour Web-based Survey

Address for correspondence: Taikyeong Ted. Jeong, Department of Computer Science and Engineering, Seoul Women's University, 621 Hwarangro, Nowon-Gu, Seoul 01797, Republic of Korea. E-mail: ttjeong@swu.ac.kr

http://dx.doi.org/10.21101/cejph.a4292

\section{INTRODUCTION}

In 2010, the US Department of Health and Human Services reported $51.8 \%$ of the population aged 12 years or older to be current alcohol drinkers (approximately 131.3 million) (1). In addition, heavy drinking was reported by $6.7 \%$ of the population aged 12 years or older (approximately 16.9 million). Among that population, $23.1 \%$ (approximately 58.6 million) participated in binge drinking at least once in the past 30 days. In 2010, rates of current alcohol use were $3.1 \%$ among adolescents aged 12 or 13 years, $12.4 \%$ among those aged 14 or 15 years, $24.6 \%$ among those aged 16 or 17 years, and $48.9 \%$ among those aged $18-20$ years (1).

In 2011, the Korea Centres for Disease Control and Prevention (KCDCP) reported that $23.7 \%$ of boys and $17.1 \%$ of girls, aged $12-18$, from the middle to high school third grade were current alcohol drinkers, which was defined as having had at least 1 alcoholic drink in the past 30 days. KCDCP also reported that the prevalence of alcohol drinking among middle and high school students is increasing year after year (2). Therefore, alcohol drinking among adolescents has become a serious social and public health problem in both the United States and South Korea $(1,2)$.

Alcohol drinking can have negative health effects such as neurological problems (i.e., dementia, stroke, and neuropathy), cardiovascular problems (i.e., myocardial infarction, cardiomyopathy, atrial fibrillation, and hypertension), psychiatric problems (i.e., depression, anxiety, and suicide), social problems (i.e., unemployment, lost productivity, and family problems), cancer (i.e., mouth, throat, esophagus, liver, colon, and breast), liver diseases (i.e., alcoholic hepatitis and cirrhosis), and other gastrointestinal problems (i.e., pancreatitis and gastritis) (3-12).

Furthermore, several studies have reported that low levels of academic achievement are associated with alcohol drinking (13-15). One potential explanation for this association is that chronic alcohol consumption leads to structural changes in the brain resulting in reduced memory and cognitive functions (16).

However, to our knowledge, there is no epidemiologic evidence among Korean adolescents regarding the association between alcohol consumption and academic achievement. Therefore, the purpose of this study was to examine whether alcohol use was related to academic achievement in Korean adolescents. 


\section{MATERIALS AND METHODS}

The Seventh Korea Youth Risk Behaviour Web-based Survey (KYRBWS-VII) was conducted in 2011. KYRBWS-VII is a cross-sectional epidemiologic study that utilizes a complex sample design with a 16-city-cluster sample strategy that covers all of South Korea. For this study, we used the national school-based survey conducted by KCDCP. This survey estimates the prevalence of risky behaviours among adolescent Korean students from middle school through high school (2). We sampled 400 middle and 400 high schools to evaluate the association between alcohol consumption and academic achievement. We also collected information on potential confounding variables such as age, body mass index, smoking, breakfast consumption, parental education level, economic status of the family, mental stress, vigorous physical activity (PA), moderate PA, and muscular strength exercises. This survey was found to be valid and reliable $(17,18)$; further details on data collection are described by KCDCP (2).

This survey was administered to a nationally representative group, and as the survey did not collect personal information, ethical approval was not required. Furthermore, all study procedures were approved by the Korea Centres for Disease Control and Prevention. Each student was assigned a unique identification number that was unknown to any of the study investigators. Students used this identification number to access the survey online. Students then indicated that they were willing to participate. We

Table 1. The characteristics of subjects

\begin{tabular}{|c|c|c|c|c|}
\hline \multicolumn{2}{|l|}{ Variables } & $\begin{array}{c}\text { Boys } \\
(\mathrm{N}=37,873)\end{array}$ & $\begin{array}{c}\text { Girls } \\
(\mathrm{N}=37,770)\end{array}$ & $\begin{array}{c}\text { Total } \\
(\mathrm{N}=75,643)\end{array}$ \\
\hline \multicolumn{2}{|l|}{ Age (years) } & $15.08 \pm 1.75$ & $15.12 \pm 1.75$ & $15.10 \pm 1.75$ \\
\hline \multicolumn{2}{|l|}{ Height (cm) } & $169.90 \pm 8.02$ & $159.99 \pm 5.36$ & $164.95 \pm 8.43$ \\
\hline \multicolumn{2}{|l|}{ Weight (kg) } & $60.51 \pm 11.67$ & $51.84 \pm 7.81$ & $56.18 \pm 10.84$ \\
\hline \multicolumn{2}{|l|}{ Body mass index $\left(\mathrm{kg} / \mathrm{m}^{2}\right)$} & $20.86 \pm 3.21$ & $20.22 \pm 2.63$ & $20.54 \pm 2.95$ \\
\hline \multirow{5}{*}{$\begin{array}{l}\text { Academic achievement } \\
\mathrm{n}(\%)\end{array}$} & Very high & $4,606(12.2)$ & $3,707(9.8)$ & $8,313(11.0)$ \\
\hline & High & $8,986(23.7)$ & $9,267(24.6)$ & $18,253(24.1)$ \\
\hline & Average & $10,055(26.6)$ & $10,320(27.3)$ & $20,375(26.9)$ \\
\hline & Low & $9,362(24.7)$ & $9,973(26.4)$ & $19,335(25.6)$ \\
\hline & Very low & $4,864(12.8)$ & $4,503(11.9)$ & $9,367(12.4)$ \\
\hline \multirow{6}{*}{$\begin{array}{l}\text { Alcohol consumption } \\
\text { frequency } n(\%)\end{array}$} & Non-drinker & $29,021(76.5)$ & $31,028(82.1)$ & $60,049(79.3)$ \\
\hline & 1-2 day(s) per month & $4,607(12.2)$ & $4,117(10.9)$ & $8,724(11.5)$ \\
\hline & $3-5$ days per month & $1,734(4.6)$ & $1,116(3.0)$ & $2,850(3.8)$ \\
\hline & 6-9 days per month & $1,120(3.0)$ & $668(1.8)$ & $1,788(2.4)$ \\
\hline & 10-19 days per month & $804(2.1)$ & $532(1.4)$ & $1,336(1.8)$ \\
\hline & 20-30 days per month & $587(1.6)$ & $309(0.8)$ & $896(1.2)$ \\
\hline \multirow{6}{*}{ Alcohol consumption n (\%) } & Non-drinker & $29,021(76.5)$ & $31,028(82.1)$ & $60,049(79.4)$ \\
\hline & $<1$ bottle of beer* & $3,182(8.5)$ & $3,111(8.3)$ & $6,293(8.3)$ \\
\hline & $1 \leq 2$ bottles of beer & $1,614(4.3)$ & $1,335(3.5)$ & $2,949(3.9)$ \\
\hline & $2 \leq 3$ bottles of beer & $949(2.5)$ & $791(2.1)$ & $1,740(2.3)$ \\
\hline & $3 \leq 4$ bottles of beer & $1,981(5.2)$ & $1,174(3.1)$ & $3,155(4.2)$ \\
\hline & $\geq 4$ bottles of beer & $1,126(3.0)$ & $331(0.9)$ & $1,457(1.9)$ \\
\hline \multirow{5}{*}{$\begin{array}{l}\text { Frequency of severe alcohol } \\
\text { intoxication } n(\%)\end{array}$} & Non-drinker & $29,021(76.5)$ & $31,028(82.1)$ & $60,049(79.4)$ \\
\hline & No severe alcohol intoxication & $7,492(19.9)$ & $5,689(15.1)$ & $13,181(17.4)$ \\
\hline & 1-2 day(s) per month & $1,003(2.7)$ & $840(2.2)$ & $1,843(2.4)$ \\
\hline & 3-4 days per month & $149(0.4)$ & $100(0.3)$ & $249(0.3)$ \\
\hline & over 5 days per month & $208(0.5)$ & $113(0.3)$ & $321(0.4)$ \\
\hline \multirow{7}{*}{ Frequency of smoking $n(\%)$} & No smoking & $31,522(83.2)$ & $35,133(93.0)$ & $66,655(88.1)$ \\
\hline & 1-2 day(s) per month & $1,076(2.8)$ & $576(1.5)$ & $1,652(2.2)$ \\
\hline & $3-5$ days per month & $477(1.3)$ & $260(0.7)$ & $737(1.0)$ \\
\hline & 6-9 days per month & $405(1.1)$ & $177(0.5)$ & $582(0.8)$ \\
\hline & 10-19 days per month & $493(1.3)$ & $244(0.6)$ & $737(1.0)$ \\
\hline & 20-29 days per month & $563(1.5)$ & $250(0.7)$ & $813(1.1)$ \\
\hline & Every day & $3,337(8.8)$ & $1,130(3.0)$ & $4,467(5.9)$ \\
\hline
\end{tabular}


Continued from the previous page

\begin{tabular}{|c|c|c|c|c|}
\hline \multicolumn{2}{|l|}{ Variables } & $\begin{array}{c}\text { Boys } \\
(\mathrm{N}=37,873)\end{array}$ & $\begin{array}{c}\text { Girls } \\
(\mathrm{N}=37,770)\end{array}$ & $\begin{array}{c}\text { Total } \\
(\mathrm{N}=75,643)\end{array}$ \\
\hline \multirow{5}{*}{ Mental stress n (\%) } & Very high & $3,619(9.6)$ & $5,472(14.5)$ & $9,091(12.0)$ \\
\hline & High & $9,928(26.2)$ & $13,098(34.7)$ & $23,026(30.4)$ \\
\hline & Average & $16,649(44.0)$ & $14,833(39.3)$ & $31,482(41.6)$ \\
\hline & Low & $6,468(17.1)$ & $3,968(10.5)$ & $10,436(13.8)$ \\
\hline & Very low & $1,209(3.2)$ & $399(1.1)$ & $1,608(2.1)$ \\
\hline \multirow{8}{*}{$\begin{array}{l}\text { Frequency of breakfast } \\
\text { consumption } \mathrm{n}(\%)\end{array}$} & No breakfast per week & $5,162(13.6)$ & $4,187(11.1)$ & $9,349(12.4)$ \\
\hline & 1 day per week & $1,974(5.1)$ & $2,174(5.8)$ & $4,121(5.4)$ \\
\hline & 2 days per week & $2,383(6.3)$ & $2,626(7.0)$ & $5,009(6.6)$ \\
\hline & 3 days per week & $2,579(6.8)$ & $2,874(7.6)$ & $5,453(7.2)$ \\
\hline & 4 days per week & $2,119(5.6)$ & $2,435(6.4)$ & $4,554(6.0)$ \\
\hline & 5 days per week & $3,286(8.7)$ & $3,789(10.0)$ & $7,075(9.4)$ \\
\hline & 6 days per week & $3,606(9.5)$ & $4,386(11.6)$ & $7,992(10.6)$ \\
\hline & Every day & $16,791(44.3)$ & $15,299(40.5)$ & $32,090(42.4)$ \\
\hline \multirow{4}{*}{$\begin{array}{l}\text { Education level of father } \\
\mathrm{n}(\%)\end{array}$} & Middle school or lower & $1,843(4.9)$ & $1,943(5.1)$ & $3,786(5.0)$ \\
\hline & High school & $12,587(33.2)$ & $13,954(36.9)$ & $26,541(35.1)$ \\
\hline & College or higher & $16,601(43.8)$ & $15,908(42.1)$ & $32,509(43.0)$ \\
\hline & Unknown & $6,842(18.1)$ & $5,965(15.8)$ & $12,807(16.9)$ \\
\hline \multirow{4}{*}{$\begin{array}{l}\text { Education level of mother } \\
n(\%)\end{array}$} & Middle school or lower & $1,765(4.7)$ & $2,025(5.4)$ & $3,790(5.0)$ \\
\hline & High school & $16,192(42.8)$ & $18,402(48.7)$ & $34,594(45.7)$ \\
\hline & College or higher & $12,723(33.6)$ & $12,022(31.8)$ & $24,745(32.7)$ \\
\hline & Unknown & $7,193(19.0)$ & $5,321(14.1)$ & $12,514(16.5)$ \\
\hline \multirow{5}{*}{$\begin{array}{l}\text { Economic status of the family } \\
n(\%)\end{array}$} & Very rich & $3,165(8.4)$ & $1,612(4.3)$ & $4,777(6.3)$ \\
\hline & Rich & $9,401(24.8)$ & $8,253(21.9)$ & $17,654(23.3)$ \\
\hline & Average & $16,929(44.7)$ & $18,833(49.9)$ & $35,762(47.3)$ \\
\hline & Poor & $6,336(16.7)$ & $7,213(19.1)$ & $13,549(17.9)$ \\
\hline & Very poor & $2,042(5.4)$ & $1,859(4.9)$ & $3,901(5.2)$ \\
\hline \multirow{6}{*}{$\begin{array}{l}\text { Frequency of vigorous } \\
\text { physical activity } n(\%)\end{array}$} & No vigorous PA & $6,095(16.1)$ & $15,942(42.2)$ & $22,037(11.0)$ \\
\hline & Once a week & $6,414(16.9)$ & $7,995(21.2)$ & $14,409(19.0)$ \\
\hline & Twice a week & $7,481(19.8)$ & $6,139(16.3)$ & $13,620(18.0)$ \\
\hline & Thrice a week & $7,111(18.8)$ & $4,097(10.8)$ & $11,208(14.8)$ \\
\hline & 4 times a week & $3,176(8.4)$ & $1,382(3.7)$ & $4,558(6.0)$ \\
\hline & 5 times a week or more & $7,596(20.1)$ & $2,215(5.9)$ & $9,811(13.0)$ \\
\hline \multirow{6}{*}{$\begin{array}{l}\text { Frequency of moderate } \\
\text { physical activity } n(\%)\end{array}$} & No moderate PA & $7,383(19.5)$ & $13,794(36.5)$ & $21,177(28.0)$ \\
\hline & Once a week & $7,276(19.2)$ & $8,776(23.2)$ & $16,052(21.2)$ \\
\hline & Twice a week & $7,752(20.5)$ & $6,851(18.1)$ & $14,603(19.3)$ \\
\hline & Thrice a week & $6,523(17.2)$ & $4,500(11.9)$ & $11,023(14.6)$ \\
\hline & 4 times a week & $2,565(6.8)$ & $1,484(3.9)$ & $4,049(5.4)$ \\
\hline & 5 times a week or more & $6,374(16.8)$ & $2,365(6.3)$ & $8,739(11.6)$ \\
\hline \multirow{6}{*}{$\begin{array}{l}\text { Frequency of muscular } \\
\text { strength exercises n (\%) }\end{array}$} & No muscular strength exercises & $13,608(35.9)$ & $25,283(66.9)$ & $38,891(51.4)$ \\
\hline & Once a week & $7,483(19.8)$ & $6,014(15.9)$ & $13,497(17.8)$ \\
\hline & Twice a week & $5,481(14.5)$ & $2,909(7.7)$ & $8,390(11.1)$ \\
\hline & Thrice a week & $4,542(12.0)$ & $1,649(4.4)$ & 6,191 (8.2) \\
\hline & 4 times a week & $1,781(4.7)$ & $628(1.7)$ & $2,409(3.2)$ \\
\hline & 5 times a week or more & 4,978 (13.1) & $1,287(3.4)$ & $6,265(8.3)$ \\
\hline
\end{tabular}

Data are expressed as mean \pm standard deviation or $n(\%)$ 
had a response rate of $95.5 \%$ (75,643 out of 79,202 students $)$ with 37,873 boys and 37,770 girls participating in this study. Characteristics of study participants are shown in Table 1.

\section{Dependent Variables}

Academic achievement was self-reported by each student using the question "What do you believe your academic achievement to be in school?". Student responses were: very high academic achievement; high academic achievement; average academic achievement; low academic achievement; and very low academic achievement. Participants were then divided into 2 groups. The first group included those who responded very high academic achievement, high academic achievement, and average academic achievement. The second group included those who reported below average academic achievement; this group was the reference group.

\section{Independent Variables}

Self-reported frequency of alcohol consumption was evaluated by the question "In the last 1 month, how often did you drink more than 1 glass?". Responses ranged from non-drinker, 1-2 day(s) per month, 3-5 days per month, 6-9 days per month, 10-19 days per month, and 20-30 days per month. Amount of alcohol consumed in the past month was evaluated as "In the last 1 month, on average, how much alcohol did you consume per drinking episode?". The response options were as follows: non-drinker, less than 1 bottle of beer or 1-2 glass(es) of Soju (Korean distilled spirits), 1 bottle of beer or 3-4 glasses of Soju, 2 bottles of beer or 5-6 glasses of Soju, 3 bottles of beer or 7-8 glasses of Soju, and 4 or more bottles of beer or $>9$ glasses of Soju. Finally, we inquired about the level of severe intoxication with the question "In the last 1 month, how often did you experience loss of memory or consciousness due to excessive alcohol consumption?". The response options were as follows: non-drinker, no severe alcohol intoxication, 1-2 day(s) per month, 3-4 days per month, and over 5 days per month.

\section{Covariate Variables}

The adolescents' age was based on the self-reported age at survey completion. The adolescents were asked to self-record their height and weight. Then, body mass index $\left(\mathrm{kg} / \mathrm{m}^{2}\right)$ was calculated from the data recorded by each student. Students reported the frequency of smoking; the answers ranged from never to everyday. Breakfast consumption was based on the number of days per week that a student eats breakfast; the answers ranged from never to everyday. Parental education level was reported as middle school or less or as college or higher education. Economic status was based on self-reported perception of wealth (very rich to very poor). Students also self-reported their perceived mental stress (very high to none). Data on physical activity (PA) was collected in 3 different ways. Responses to questions on the frequency of vigorous PA ranged from never to over 5 days a week of activities such as digging, aerobics, heavy lifting, or fast cycling during the week. Similarly, responses to questions on the frequency of moderate PA ranged from never to over 5 days a week of activities such as cycling at a regular pace, carrying light loads or playing doubles tennis during the week. Number of days of muscular strength exercises such as sit-ups, push-ups, and weight lifting or weight training, was also recorded as number of days a week the student engaged in that activity.

\section{Statistical Analysis}

Results for this study are presented as means and standard deviations. We conducted multivariate logistic regression analyses to determine the association between alcohol consumption and academic achievement while controlling for potential confounding variables such as age, body mass index, smoking, breakfast consumption, parental education level, economic status of the family, mental stress, vigorous PA, moderate PA, and muscular strength exercises. All analyses were performed using SPSS Complex SampleTM version 18.0 (Chicago, IL, USA) and statistical significance was set at $\mathrm{p}<0.05$.

\section{RESULTS}

Results of the three different multivariate logistic regression models for assessing academic achievement in relation to frequency of alcohol consumption, amount of alcohol consumed, and number of days per month of severe alcohol intoxication are shown in Tables 2, 3 and 4, respectively.

For boys, achieving average or higher academic performance decreased with increasing number of days per month of alcohol consumption. Boys who consumed alcohol 3-5 day(s) per month had 0.83 lower odds of achieving average or higher academic performance than non-drinkers (odds ratio (OR) 0.83; $95 \%$ confidence interval $(\mathrm{CI}) 0.72-0.95 ; \mathrm{p}=0.008)$. The odds of achieving average or higher academic performance steadily declined with increasing number of days of alcohol consumption from 6-9 days per month (OR 0.64; 95\% CI 0.55-0.76; $\mathrm{p}<0.001$ ) to $10-19$ days per month (OR $0.74 ; 95 \%$ CI $0.61-0.91 ; p=0.004)$. For girls, the odds for achieving average or higher academic performance according to the number of days per month that alcohol was consumed decreased more consistently from 1-2 day(s) per month (OR $0.74 ; 95 \%$ CI $0.68-0.80 ; \mathrm{p}<0.001)$ to $20-30$ days per month (OR $0.5395 \%$ CI $0.38-0.73 ; \mathrm{p}<0.001$ ), compared to non-drinkers (Table 2).

For boys, the odds for achieving average or higher academic performance according to the amount of alcohol consumed were the lowest with lower consumption, 1 to $<2$ bottles of beer (OR $0.84 ; 95 \%$ CI $0.73-0.96 ; p=0.014)$, and highest with higher consumption, 3 to $\geq 4$ bottles of beer (OR $0.82 ; 95 \%$ CI $0.72-0.95$; $\mathrm{p}=0.006$ ), compared to non-drinkers. The odds of achieving average or higher academic performance were the lowest with $18 \%$ decreased odds of high academic performance for those who consumed 2-3 bottles of beer. Among girls, the odds for achieving average or higher academic performance was lower for girls who consumed any amount of alcohol, compared to non-drinkers (OR $0.66-0.73, \mathrm{p} \leq 0.026$ ) (Table 3).

Among boys and girls, the odds for achieving average or higher academic performance were the lowest for those who drank 1-2 days per month, compared to non-drinkers (OR 0.70; $95 \%$ CI $0.60-0.82 ; \mathrm{p}<0.001$ in boys, OR $0.53 ; 95 \%$ CI $0.44-0.65$; $\mathrm{p}<0.001$ in girls) (Table 4). 
Table 2. Academic achievement among Korean adolescents in relation to alcohol consumption frequencies $(N=75,643)$

\begin{tabular}{|c|c|c|c|c|c|c|c|}
\hline \multirow{2}{*}{\multicolumn{2}{|c|}{ Alcohol consumption frequencies }} & \multicolumn{6}{|c|}{ Below average academic achievement vs. average academic achievement or higher } \\
\hline & & \multirow{2}{*}{$\frac{n}{29,021}$} & \multirow{2}{*}{$\frac{B}{\text { Ref }}$} & \multirow[t]{2}{*}{ SE } & \multirow{2}{*}{$\begin{array}{c}\text { OR } \\
1.00\end{array}$} & \multirow[t]{2}{*}{$95 \% \mathrm{Cl}$} & \multirow[t]{2}{*}{$p$-value } \\
\hline \multirow{6}{*}{ Boys } & Non-drinker & & & & & & \\
\hline & $1-2$ day(s) per month & 4,607 & -0.023 & 0.043 & 0.98 & $0.90-1.06$ & 0.595 \\
\hline & $3-5$ days per month & 1,734 & -0.187 & 0.070 & 0.83 & $0.72-0.95$ & $0.008^{* *}$ \\
\hline & $6-9$ days per month & 1,120 & -0.439 & 0.085 & 0.64 & $0.55-0.76$ & $<0.001^{* * *}$ \\
\hline & $10-19$ days per month & 804 & -0.298 & 0.104 & 0.74 & $0.61-0.91$ & $0.004^{* *}$ \\
\hline & 20-30 days per month & 587 & -0.061 & 0.106 & 0.94 & $0.76-1.16$ & 0.566 \\
\hline \multirow{6}{*}{ Girls } & Non-drinker & 31,028 & Ref & & 1.00 & & \\
\hline & 1-2 day(s) per month & 4,117 & -0.306 & 0.043 & 0.74 & $0.68-0.80$ & $<0.001^{* * *}$ \\
\hline & $3-5$ days per month & 1,116 & -0.388 & 0.082 & 0.68 & $0.58-0.80$ & $<0.001^{* * *}$ \\
\hline & $6-9$ days per month & 668 & -0.565 & 0.100 & 0.57 & $0.47-0.69$ & $<0.001^{* * *}$ \\
\hline & $10-19$ days per month & 532 & -0.590 & 0.116 & 0.55 & $0.44-0.70$ & $<0.001^{* * *}$ \\
\hline & 20-30 days per month & 309 & -0.639 & 0.166 & 0.53 & $0.38-0.73$ & $<0.001^{* * *}$ \\
\hline
\end{tabular}

$\mathrm{SE}$ - standard error; OR - odd ratio; $\mathrm{Cl}$ - confidence interval

${ }^{* *} p<0.01,{ }^{* * *} p<0.001$; tested by multivariable logistic regression analysis after adjusting for covariates such as age, body mass index, frequency of smoking, frequency of breakfast consumption, education level of parents, economic status of the family, mental stress, and frequency of vigorous physical activity, moderate physical activity, and muscular strength exercises

Table 3. Academic achievement in relation to alcohol consumption among Korean adolescents $(N=75,643)$

\begin{tabular}{|c|c|c|c|c|c|c|c|}
\hline \multirow{2}{*}{\multicolumn{2}{|c|}{ Alcohol consumption }} & \multicolumn{6}{|c|}{ Below average academic achievement vs. average academic achievement or higher } \\
\hline & & \multirow{2}{*}{$\frac{n}{29,021}$} & \multirow{2}{*}{$\frac{\beta}{\operatorname{Ref}}$} & \multirow{2}{*}{ SE } & \multirow{2}{*}{$\frac{\mathrm{OR}}{1.00}$} & \multirow{2}{*}{$95 \% \mathrm{Cl}$} & \multirow{2}{*}{ p-value } \\
\hline \multirow{6}{*}{ Boys } & Non-drinker & & & & & & \\
\hline & $<1$ bottle of beer & 3,182 & -0.072 & 0.048 & 0.93 & $0.85-1.02$ & 0.130 \\
\hline & $1 \leq 2$ bottles of beer & 1,614 & -0.175 & 0.070 & 0.84 & $0.73-0.96$ & $0.014^{*}$ \\
\hline & $2 \leq 3$ bottles of beer & 949 & -0.202 & 0.088 & 0.82 & $0.69-0.97$ & $0.023^{*}$ \\
\hline & $3 \leq 4$ bottles of beer & 1,981 & -0.194 & 0.071 & 0.82 & $0.72-0.95$ & $0.006^{\star *}$ \\
\hline & $\geq 4$ bottles of beer & 1,126 & -0.040 & 0.086 & 0.96 & $0.81-1.14$ & 0.642 \\
\hline \multirow{6}{*}{ Girls } & Non-drinker & 31,028 & Ref & & 1.00 & & \\
\hline & $<1$ bottle of beer & 3,111 & -0.372 & 0.043 & 0.69 & $0.63-0.75$ & $<0.001^{* * *}$ \\
\hline & $1 \leq 2$ bottles of beer & 1,335 & -0.356 & 0.071 & 0.70 & $0.61-0.81$ & $<0.001^{* * *}$ \\
\hline & $2 \leq 3$ bottles of beer & 791 & -0.315 & 0.095 & 0.73 & $0.61-0.88$ & $0.001^{* *}$ \\
\hline & $3 \leq 4$ bottles of beer & 1,174 & -0.411 & 0.090 & 0.66 & $0.56-0.79$ & $<0.001^{* * *}$ \\
\hline & $\geq 4$ bottles of beer & 331 & -0.374 & 0.168 & 0.69 & $0.50-0.96$ & $0.026^{*}$ \\
\hline
\end{tabular}

$\mathrm{SE}$ - standard error; OR - odd ratio; $\mathrm{Cl}$ - confidence interval

${ }^{*} p<0.05,{ }^{* *} p<0.01,{ }^{* * *} p<0.001$; tested by multivariable logistic regression analysis after adjusting for covariates such as age, body mass index, frequency of smoking, frequency of breakfast consumption, education level of parents, economic status of the family, mental stress, and frequency of vigorous physical activity, moderate physical activity, and muscular strength exercises

\section{DISCUSSION}

Our study sought to examine the relationship between alcohol consumption and academic achievement in Korea adolescents. We found that alcohol consumption had negative association, and increased alcohol consumption decreased academic achievement in adolescents even after controlling covariates.

Previous studies found that alcohol drinkers experienced more difficulties as to the problem solving, flexibility of cognitive, working memory, repetitive responding, self-regulation, and demonstrated prefrontal neuro-behavioural dysfunction (19-21). Furthermore, subjects with alcoholism demonstrated deficits in explicit memory, visuospatial processes, and motor control (i.e., gait, speed and balance) $(22,23)$.

Interestingly, magnetic resonance imaging (MRI) studies have confirmed that alcohol drinkers have volume deficits in the cortical region, corpus callosum, cerebellar white matter, and anterior hippocampus (24-27). Alcohol intake can cause structural and functional changes in the brain leading to decreased brain activity and functioning.

In addition, academic achievement is related to brain activity and functioning. Specifically, listening, reading, speaking, and writing during school decrease with a decrease in brain activity and functioning. Our results show that both boys and girls with 
Table 4. Academic achievement in relation to frequency of severe alcohol intoxication among Korean adolescents $(N=75,643)$

\begin{tabular}{|c|c|c|c|c|c|c|c|}
\hline \multirow{2}{*}{\multicolumn{2}{|c|}{ Frequency of severe alcohol intoxication }} & \multicolumn{6}{|c|}{ Below average academic achievement vs. average academic achievement or higher } \\
\hline & & \multirow{2}{*}{$\frac{n}{29,021}$} & \multirow{2}{*}{$\frac{\beta}{\text { Ref }}$} & \multirow[t]{2}{*}{ SE } & \multirow{2}{*}{$\frac{\text { OR }}{1.00}$} & \multirow[t]{2}{*}{$95 \% \mathrm{Cl}$} & \multirow[t]{2}{*}{ p-value } \\
\hline \multirow{5}{*}{ Boys } & Non-drinker & & & & & & \\
\hline & No severe alcohol intoxication & 7,492 & -0.101 & 0.039 & 0.90 & $0.84-0.98$ & $0.009^{* *}$ \\
\hline & 1-2 day(s) per month & 1,003 & -0.357 & 0.081 & 0.70 & $0.60-0.82$ & $<0.001^{* * *}$ \\
\hline & 3-4 days per month & 149 & -0.192 & 0.220 & 0.83 & $0.54-1.27$ & 0.384 \\
\hline & over 5 days per month & 208 & 0.109 & 0.192 & 1.12 & $0.77-1.63$ & 0.571 \\
\hline \multirow{5}{*}{ Girls } & Non-drinker & 31,028 & Ref & & 1.00 & & \\
\hline & No severe alcohol intoxication & 5,689 & -0.336 & 0.039 & 0.71 & $0.66-0.77$ & $<0.001^{* * *}$ \\
\hline & 1-2 day(s) per month & 840 & -0.631 & 0.099 & 0.53 & $0.44-0.65$ & $<0.001^{* * *}$ \\
\hline & 3-4 days per month & 100 & -0.554 & 0.287 & 0.58 & $0.33-1.01$ & 0.054 \\
\hline & over 5 days per month & 113 & -0.617 & 0.315 & 0.54 & $0.29-1.00$ & 0.051 \\
\hline
\end{tabular}

SE - standard error; OR - odd ratio; $\mathrm{Cl}$ - confidence interval

${ }^{* *} \mathrm{p}<0.01,{ }^{* * *} \mathrm{p}<0.001$; tested by multivariable logistic regression analysis after adjusting for covariates such as age, body mass index, frequency of smoking, frequency of breakfast consumption, education level of parents, economic status of the family, mental stress, and frequency of vigorous physical activity, moderate physical activity, and muscular strength exercises

high levels of alcohol consumption are more likely to have below average academic achievement in Korea.

In both boys and girls who consume alcohol, academic achievement is inversely associated with alcohol consumption; the more the alcohol consumed the lower the level of academic achievement. Interestingly, when alcohol consumption increased, girls showed a stronger inverse association with academic achievement than boys (Table 2-4). Based on this result, we assume that alcohol consumption affects girls more significantly than boys. This may be because boys are physiologically more developed than girls (28). However, additional studies should be conducted to determine the effects of alcohol consumption by gender.

There are several limitations in this study. First, the students reported the parental education level and economic status of their families, which may be inaccurate. Second, adolescents self-reported their height and weight and these variables were not directly measured. Therefore, the body mass index of subjects might be lower, because adolescents tend to increase in height and decrease in weight (29). Third, KYRBWS-VII is a cross-sectional study. Therefore, we cannot make any causal inference. We can only discuss the interrelationship between academic achievement and alcohol consumption. However, the fact that we investigated all of South Korea and had a large sample size is a strength of this study. Therefore, we assume that the results could represent the true relationship between alcohol consumption and academic achievement in Korean adolescents.

\section{CONCLUSION}

In Korea, both boys and girls who increase their alcohol consumption were found to have lower than average academic achievement. To improve academic achievement, we recommend interventions that may reduce alcohol consumption among adolescents in Korea.

\section{Acknowledgements}

This work has been supported by the Basic Science Research Program through NRF of Korea 2014R1A1A2058886.
This research was supported by a special research grant of Seoul Women's University in 2016.

\section{Conflict of Interests}

None declared

\section{REFERENCES}

1. U.S. Department of Health and Human Services. Results from the 2010 National Survey on Drug Use and Health: Summary of National Findings [Internet]. Atlanta: U.S. Department of Health and Human Services; 2011 [cited 2015 Nov 30]. Available from: http://www.samhsa. gov/data/sites/default/files/NSDUHNationalFindingsResults2010web/2k10ResultsRev/NSDUHresultsRev2010.pdf.

2. Korea Centers for Disease Control and Prevention. The Seventh Korea Youth Risk Behavior Web-based Survey in 2011. Seoul: Ministry of Education, Science and Technology, Ministry of Health and Welfare, Korea Centers for Disease Control and Prevention; 2012. (In Korean.)

3. Corrao G, Bagnardi V, Zambon A, La Vecchia C. A meta-analysis of alcohol consumption and the risk of 15 diseases. Prev Med. 2004 May;38(5):613-9.

4. Corrao G, Rubbiati L, Zambon A, Aricò, S. Alcohol-attributable and alcohol-preventable mortality in Italy. A balance in 1983 and 1996. Eur J Public Health. 2002 Sep;12(3):214-23.

5. Rehm J, Gmel G, Sempos CT, Trevisan M. Alcohol-related morbidity and mortality. Alcohol Res Health. 2003;27(1):39-51.

6. Castaneda R, Sussman N, Westreich L, Levy R, O'Malley M. A review of the effects of moderate alcohol intake on the treatment of anxiety and mood disorders. J Clin Psychiatry. 1996 May;57(5):207-12.

7. Booth BM, Feng W. The impact of drinking and drinking consequences on short-term employment outcomes in at-risk drinkers in six southern states. J Behav Health Serv Res. 2002 May;29(2):157-66.

8. Leonard KE, Rothbard JC. Alcohol and the marriage effect. J Stud Alcohol Suppl. 1999 Mar;13:139-46.

9. Baan R, Straif K, Grosse Y, Secretan B, El Ghissassi F, Bouvard V, et al. Carcinogenicity of alcoholic beverages. Lancet Oncol. 2007 Apr;8(4):292-3.

10. Heron M. Deaths: leading causes for 2004. Natl Vital Stat Rep. 2007 Nov;56(5):1-95.

11. Lesher SD, Lee YT. Acute pancreatitis in a military hospital. Mil Med. 1989 Nov;154(11):559-64.

12. Kelly JP, Kaufman DW, Koff RS, Laszlo A, Wilholm BE, Shapiro, S. Alcohol consumption and the risk of major upper gastrointestinal bleeding. Am J Gastroenterol. 1995 Jul;90(7):1058-64.

13. Hayatbakhsh MR, Najman JM, Bor W, Clavarino A, Alati R. School performance and alcohol use problems in early adulthood: a longitudinal study. Alcohol. 2011 Nov;45(7):701-9. 
14. López-Frías M, de la fe Fernandez M, Planells E, Miranda MT, Mataix J, Llopis J. Alcohol consumption and academic performance in a population of Spanish high school students. J Stud Alcohol. 2001 Nov;62(6):741-4

15. Miller P, Plant M. Truancy and perceived school performance: an alcohol and drug study of UK teenagers. Alcohol Alcohol. 1999 NovDec;34(6):886-93.

16. Zahr NM, Kaufman KL, Harper CG. Clinical and pathological features of alcohol-related brain damage. Nat Rev Neurol. 2011 May;7(5):284-94

17. Bae J, Joung H, Kim JY, Kwon KN, Kim Y, Park SW. Validity of selfreported height, weight, and body mass index of the Korea Youth Risk Behavior Web-based Survey questionnaire. J Prev Med Public Health. 2010 Sep;43(5):396-402.

18. Bae J, Joung H, Kim JY, Kwon KN, Kim YT, Park SW. Test-retest reliability of a questionnaire for the Korea Youth Risk Behavior Web-based Survey. J Prev Med Public Health. 2010 Sep;43(5):403-10.

19. Dirksen CL, Howard JA, Cronin-Golomb A, Oscar-Berman M. Patterns of prefrontal dysfunction in alcoholics with and without Korsakoff's syndrome, patients with Parkinson's disease, and patients with rupture and repair of the anterior communicating artery. Neuropsychiatr Dis Treat. 2006 Sep;2(3):327-39.

20. Oscar-Berman M. Neuropsychological vulnerabilities in chronic alcoholism. In: Noronha A, Eckardt M, Warren K, editors. Review of NIAAA's neuroscience and behavioral research portfolio: NIAAA Research Monograph No. 34 [Internet]. Bethesda, MD: U.S. Department of Health and Human Services, Public Health Service, National Institutes of Health, National Institute on Alcohol Abuse and Alcoholism; 2000. p. 437-71 [cited 2015 Nov 30]. Available from: http://archive.org/details/reviewofniaaasne00noro.

21. Oscar-Berman M, Ellis RJ. Cognitive deficits related to memory impairments in alcoholism. Recent Dev Alcohol. 1987;5:59-80
22. Green A, Garrick T, Sheedy D, Blake H, Shores EA, Harper C. The effect of moderate to heavy alcohol consumption on neuropsychological performance as measured by the repeatable battery for the assessment of neuropsychological status. Alcohol Clin Exp Res. 2010 Mar;34(3):44350 .

23. Sullivan EV, Harris RA, Pfefferbaum A. Alcohol's effects on brain and behavior. Alcohol Res Health. 2010;33(1-2):127-43.

24. Agartz I, Momenan R, Rawlings RR, Kerich MJ, Hommer DW. Hippocampal volume in patients with alcohol dependence. Arch Gen Psychiatry. 1999 Apr;56(4):356-63.

25. Cardenas VA, Studholme C, Gazdzinski S, Durazzo TC, Meyerhoff DJ. Deformation-based morphometry of brain changes in alcohol dependence and abstinence. Neuroimage. 2007 Feb;34(3):879-87.

26. Pfefferbaum A, Lim KO, Desmond JE, Sullivan EV. Thinning of the corpus callosum in older alcoholic men: a magnetic resonance imaging study. Alcohol Clin Exp Res. 1996 Jun;20(4):752-7.

27. Phillips SC, Harper CG, Kril J. A quantitative histological study of the cerebellar vermis in alcoholic patients. Brain. 1987 Apr;110(Pt 2):301-14.

28. Christie D, Viner R. Adolescent development. BMJ. 2005 Feb;330(7486):301-4.

29. Sherry B, Jefferds ME, Grummer-Strawn LM. Accuracy of adolescent self-report of height and weight in assessing overweight status: a literature review. Arch Pediatr Adolesc Med. 2007 Dec;161(12):1154-61.

Received February 3, 2015 Accepted in revised form December 31, 2015 